\section{Exploring Dietary Patterns in the Southernmost Limit of Prehispanic Agriculture in America by Using Bayesian Stable Isotope Mixing Models}

Valeria Bernal, Paula N. Gonzalez, Florencia Gordón, and S. Ivan Perez

Consejo Nacional de Investigaciones Científicas y Técnicas (CONICET), Facultad de Ciencias Naturales y Museo, Universidad Nacional de La Plata, 122 y 60, 1900, La Plata, Argentina (bernal.valeria@gmail.com, bernalv@fcnym.unlp .edu.ar). This paper was submitted 5 III 15, accepted 27 IV 15, and electronically published 4 III 16.

CA+ Online-Only Material: Supplement A

The contribution of maize to the diet of prehispanic populations that inhabited Mendoza Province, the thensouthernmost limit of agriculture in America, has been largely debated. Recently, on the basis of $\delta^{13} \mathrm{C}$ data, it was suggested that cacti may mimic the pattern of human isotopic values attributed to maize consumption in this region. These studies relied on a univariate qualitative approach not suitable for accurately identifying dietary contribution when multiple potential resources are available. Here, we analyzed published $\delta^{13} \mathrm{C}$ and $\delta^{15} \mathrm{~N}$ data by using Bayesian mixing models to estimate the proportional contributions of different plants and animals to the protein component and total diet. The effect of different fractionation values on these estimations was also assessed. Our results pointed out the importance of $\mathrm{C}_{3}$ vegetables in the prehispanic diet of these populations and only a small contribution of maize in the later Late Holocene sample from North Mendoza. Fractionation values had a significant effect on diet estimation. Overall, our study highlights the importance of obtaining fractionation values for local resources and increasing the diversity of isotopes analyzed for both the consumer and the potential resources to get a better understanding of diet variation in this region.

The center-north of Mendoza Province in Argentina has been proposed as the southernmost limit of prehispanic agriculture in America. Two main lines of evidence have been used to support this hypothesis: the macroremains of maize (Zea mays) found in archaeological sites dated to around 2,000 years ago and the $\delta^{13} \mathrm{C}$ isotopic values of human remains, which are consistent with the expected values if $\mathrm{C}_{4}$ plants, such as maize, were incorporated into the diet (Gil, Neme, and Tykot 2011; Gil et al. 2006, 2014; Lagiglia 2001). The inferences made on the

(C) 2016 by The Wenner-Gren Foundation for Anthropological Research. All rights reserved. 0011-3204/2016/5702-0008\$10.00. DOI: 10.1086 1685560 basis of isotopic values assume that maize was the most important source of $\delta^{13} \mathrm{C}$-enriched carbon in this region. Results from a recent study raised an interesting alternative for explaining the human isotopic values by showing that $\delta^{13} \mathrm{C}$ values of four species of edible cacti (crassulacean acid metabolism [CAM] plants) overlap the range of $\mathrm{C}_{4}$ photosynthesizers (Llano and Ugan 2014). On the basis of procurement, processing, and nutritional data for these species, the authors suggest that this source was available for prehistoric populations and might have contributed up to $20 \%$ of their diet. Moreover, Llano and Ugan (2014) argue that even lower levels of CAM-plant consumption may mimic the pattern of isotopically mixed diets often attributed to maize use in this region.

The studies performed to date have based the reconstruction of prehispanic diets on univariate qualitative comparisons of the difference between the values of the potential resource and the consumer for each trace element in the isotopic niche space, using a single fractionation or discrimination value for every resource (Gil, Neme, and Tykot 2011; Gil et al. 2014; Llano and Ugan 2014). This procedure has been widely criticized because it cannot accurately identify dietary contributions when more than one potential resource is available and because it does not take into account uncertainty and variation in trophic fractionation and isotopic values, ignoring much of the inherent variability in natural systems (Layman et al. 2012). Therefore, a better estimation of variation in diet composition in the center-north of Mendoza requires the conjoint analysis of different isotopes, from humans and resources, using a multivariate quantitative approach that allows us to model the complexity of the phenomena.

Bayesian models have recently been proposed as a rigorous method for assessing contributions of resource pools with isotope data (Moore and Semmens 2008; Parnell et al. 2013; Semmens et al. 2009). Their main advantages over other methods is that Bayesian mixing models allow us to estimate the proportions of several resources in the diets of consumers, incorporating available prior information and providing posterior probability distributions for each resource, that is, which sources are more or less likely to explain variation in a consumer's isotope values. In this report, we analyze the proportional contributions of different plant and animal sources to the protein component, as well as the total diet, in the southern frontier of agriculture spread in America by applying Bayesian mixing models, and we evaluate the effect of variation in the fractionation values on the proportions estimated (Bocherens and Drucker 2003; Froehle, Kellner, and Schoeninger 2010; Tykot et al. 2009).

\section{Diet Estimation Using Bayesian Mixing Models}

The qualitative approach, as well as the more strict geometric method based on the distances between consumer 
and resources in the isotopic niche space, fails to accurately identify dietary contributions when the number of potential resources increases, because multiple combinations (in number and proportion) of resources might result in the observed isotopic value of the consumer (Phillips 2001; Schwarcz 1991). Moreover, it tends to overestimate rare items and underestimate those more commonly consumed (Layman et al. 2012). In order to overcome these limitations, stable-isotope mixture or mixing models were developed for estimating proportional source contributions to the diets of consumers (Phillips and Gregg 2001). For the case of a consumer ( $c$; or mixture) with two isotopes $(X, Y)$ and three sources, a mass-balance or linear mixing model is described by the following equations (Phillips 2001; Schwarcz 1991):

$$
\begin{aligned}
\delta X c & =f_{1} \delta X_{1}+f_{2} \delta X_{2}+f_{3} \delta X_{3}, \\
\delta Y c & =f_{1} \delta Y_{1}+f_{2} \delta Y_{2}+f_{3} \delta Y_{3}, \\
1 & =f_{1}+f_{2}+f_{3} .
\end{aligned}
$$

The solution of this system of equations gives three proportions of the contribution of the resources $\left(f_{1}, f_{2}\right.$, and $\left.f_{3}\right)$ for the consumer $(c)$ when the isotopic values $X$ and $Y$ are known for consumers and resources (the latter adjusted to account for isotopic fractionation; Hopkins and Ferguson 2012; Phillips 2001). The relative contribution of food resources can be determined by this linear mixing model only when the number of resources does not exceed the number of isotopes by more than 1 . Because most food webs are complex, they usually have more resources than tracer elements, and thus there are multiple likely solutions for combinations of resource contributions. In such cases, deterministic mixing models that generate exact values for proportional contributions of each resource are not suitable, and models that inform the probability of contributions represent a more adequate alternative (Hopkins and Ferguson 2012; Layman et al. 2012; Parnell et al. 2013).

More recently, stable-isotope mixing models were placed into a Bayesian statistical approach, which allows for several useful extensions in a flexible and intuitive estimation framework (Hopkins and Ferguson 2012; Parnell et al. 2013). In particular, Bayesian mixing models improved diet analysis by estimating probability distributions of resource contributions to a consumer or mixture while explicitly accounting for uncertainty associated with multiple sources, fractionation values, and isotope signatures (Hopkins and Ferguson 2012; Moore and Semmens 2008; Parnell et al. 2013). Moreover, these models can also include more sources than $N+1$ isotopes, prior information, and a hierarchical structure (Hopkins and Ferguson 2012; Parnell et al. 2013). As outputs, the more recent Bayesian models infer the joint posterior probability of resource proportions used by individual and group of consumers, using a Markov chain Monte Carlo (MCMC) algorithm, as well as an estimation of the joint behavior of the resource proportions that is useful in determining the degree of independence among resources. Despite their advantages, only recently have archaeologists begun to use these sophisticated models for diet estimation (Arcini, Ahström, and Tagesson 2014; Drake et al. 2014).

To evaluate the contribution of food sources to the human diet in populations from Mendoza, considering the uncertainty associated with multiple resources, fractionation values, and isotope signatures, we applied the MixSIAR hierarchical model, which extends the Bayesian models to multivariate data incorporating fixed and random effects associated with the consumers (Parnell et al. 2013; Stock and Semmens 2013). The analyses were carried out in the MixSIAR graphical user interface for R (Stock and Semmens 2013), setting populations and individuals as random effects. We specified the MCMC algorithm, using the default parameters that correspond to the "very long" option. Three parallel chains, with an MCMC for each chain of 1,000,000 generations (attaining $3,000,000$ generations), were used. As suggested by Stock and Semmens (2013), the first 700,000 generations were removed as burn-in and the sample frequency was established in 300 generations. After running the analysis, we determined, using the trace plots and the Gelman-Rubin and Geweke diagnostic tests, that the MCMC converged on the posterior distributions for all variables.

The input variables for the models were obtained from large and publicly available data sets with 154 values of $\delta^{13} \mathrm{C}$ and $\delta^{15} \mathrm{~N}$ in archaeological and modern plants and animals (resources) from Mendoza Province. The human data (consumers) correspond to isotopic values from collagen (col) and apatite (ap) of 97 adults that were grouped into six samples corresponding to three geographic areas (North, Center, and South Mendoza) and two time periods (>1,500 and 1,500200 years BP; fig. 1; for a detailed description of the samples, see Gil, Neme, and Tykot 2011; Gil et al. 2014; Salgán et al. 2012). These chronological periods were established on the basis of the most reliable evidence of the presence of cultigens in the region. The food sources included in this study are maize (Zea mays), one group of cacti (Cereus, Maihueniopsis, Opuntia, and Pterocactus), animals (Lama guanicoe, Pterocnemia pennata, and the small rodents Ctenomys, Galea, Cavia, and Microcavia), and one group of $\mathrm{C}_{3}$ plants (Lagenaria, Cucurbita, Geoffroea, Prosopis, Phaseolus, Schinus, and Cassia; the isotopic values were taken from Gil, Neme, and Tykot 2011; Gil et al. 2014; Llano and Ugan 2014).

Because of the lack of agreement in the literature about the fractionation values of $\delta^{13} \mathrm{C}$ and $\delta^{15} \mathrm{~N}$ for different types of resources (ranging from $+1 \%$ to $+5 \%$ ), the analyses were repeated, using four configurations of values derived from well-monitored observational and experimental studies (table 1; Bocherens and Drucker 2003; Froehle, Kellner, and Schoeninger 2010; Hare et al. 1991; Jim et al. 2006; Tykot et al. 2009). Two of the four configurations (B and C) correspond to values that are commonly used in paleodietary analysis in the region of study (e.g., Gil et al. 2014; Tessone et al. 2009). They assume that the fractionation is constant for all resources and are based on values reported by Tykot et al. (2009) and Bocherens and 


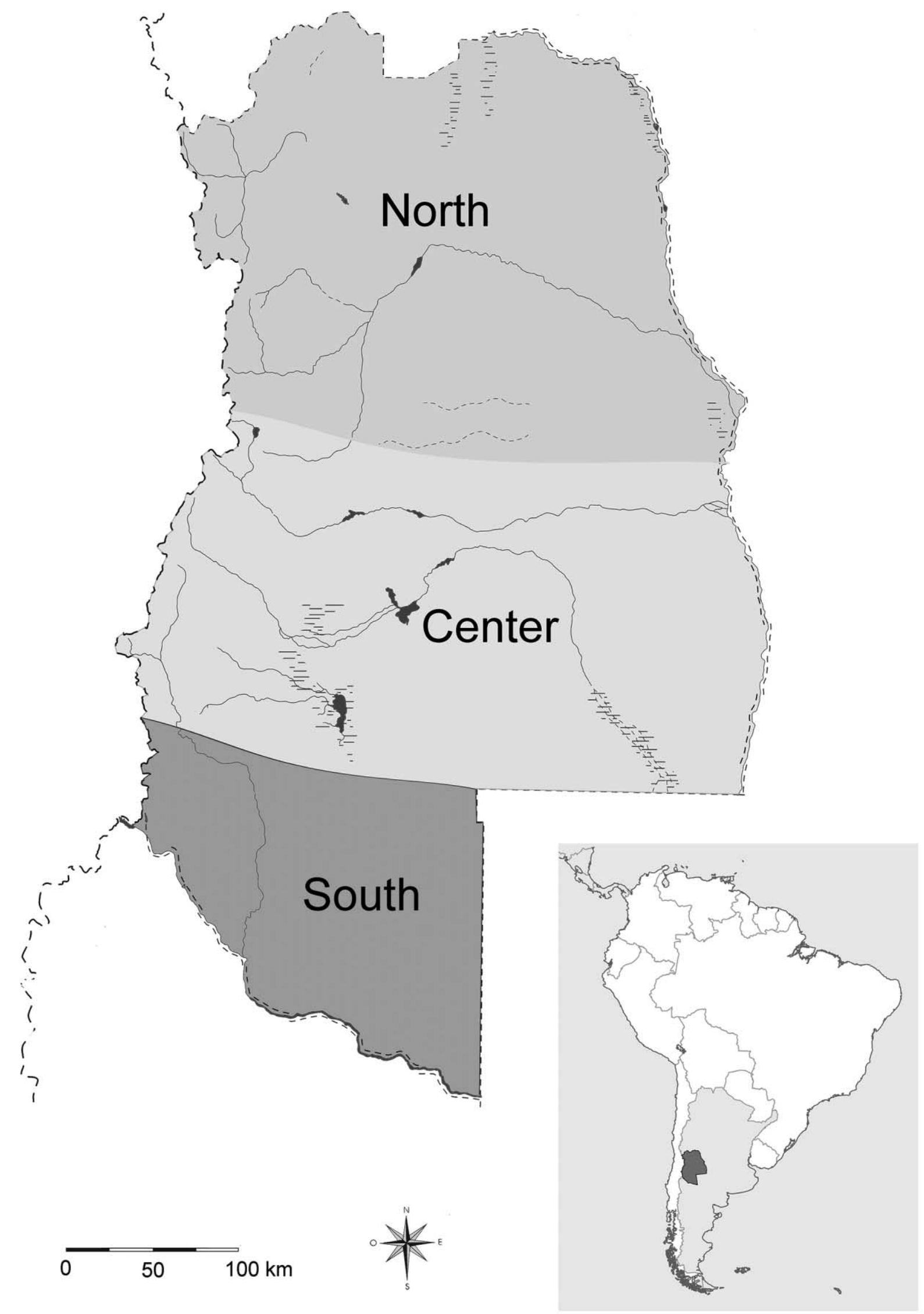

Figure 1. Map of Mendoza province, showing the three geographic areas studied here. A color version of this figure is available online. 
Table 1. Sets of fractionation values used in the mixing models

\begin{tabular}{lccc}
\hline & \multicolumn{3}{c}{ Fractionation values } \\
\cline { 2 - 4 } Configuration of & & \\
fractionation, resource & $\delta^{13} \mathrm{C}_{\mathrm{col}}$ & $\delta^{15} \mathrm{~N}$ & $\delta^{13} \mathrm{C}_{\mathrm{ap}}$ \\
\hline $\mathrm{A}^{\mathrm{a}}$ : & & & \\
$\quad$ Animals & $1.0 \pm .3$ & $4.0 \pm 1.0$ & $8.0 \pm .3$ \\
$\quad \mathrm{C}_{3}$ plants & $3.9 \pm 1.4$ & $2.2 \pm .3$ & $10.9 \pm 1.4$ \\
$\quad$ Cacti & $3.7 \pm 1.4$ & $2.3 \pm .3$ & $10.7 \pm 1.4$ \\
$\quad$ Maize & $3.7 \pm 1.4$ & $2.3 \pm .3$ & $10.7 \pm 1.4$ \\
$\mathrm{~B}^{\mathrm{b}}$ : & & & \\
$\quad$ Animals & $1.0 \pm .3$ & $4.0 \pm 1.0$ & $8.0 \pm .3$ \\
$\quad \mathrm{C}_{3}$ plants & $1.0 \pm .3$ & $4.0 \pm 1.0$ & $8.0 \pm .3$ \\
$\quad$ Cacti & $1.0 \pm .3$ & $4.0 \pm 1.0$ & $8.0 \pm .3$ \\
$\quad$ Maize & $1.0 \pm .3$ & $4.0 \pm 1.0$ & $8.0 \pm .3$ \\
$\mathrm{C}^{\mathrm{c}}$ : & & & \\
$\quad$ Animals & $5.0 \pm 1.5$ & $4.0 \pm 1.0$ & $12.0 \pm 1.5$ \\
$\quad \mathrm{C}_{3}$ plants & $5.0 \pm 1.5$ & $4.0 \pm 1.0$ & $12.0 \pm 1.5$ \\
$\quad$ Cacti & $5.0 \pm 1.5$ & $4.0 \pm 1.0$ & $12.0 \pm 1.5$ \\
$\quad$ Maize & $5.0 \pm 1.5$ & $4.0 \pm 1.0$ & $12.0 \pm 1.5$ \\
$\mathrm{D}^{\mathrm{d}}$ : & & & \\
$\quad$ Animals & $1.0 \pm .3$ & $4.0 \pm 1.0$ & $8.0 \pm .3$ \\
$\quad \mathrm{C}_{3}$ plants & $3.2 \pm 1.4$ & $2.2 \pm .3$ & $10.2 \pm .3$ \\
Cacti & $1.4 \pm .3$ & $2.3 \pm .3$ & $8.4 \pm 1.4$ \\
$\quad$ Maize & $1.4 \pm .3$ & $2.3 \pm .3$ & $8.4 \pm 1.4$ \\
\hline & & &
\end{tabular}

Note. ap = apatite; col = collagen.

a Bocherens and Drucker (2003); Froehle, Kellner, and Schoeninger (2010); Hare et al. (1991); Tykot et al. (2009).

${ }^{\mathrm{b}}$ Bocherens and Drucker (2003); Tykot et al. (2009).

c Tykot et al. (2009).

d Bocherens and Drucker (2003); Hare et al. (1991); Tykot et al. (2009).

Drucker (2003). Alternatively, the other two sets (A and D) are more realistic because they assign specific fractionation values to different resources. Configurations $\mathrm{A}$ and $\mathrm{D}$ differ in the fractionation values of $\delta^{13} \mathrm{C}_{\text {col }}$ for plant resources, according to the estimations made by Froehle, Kellner, and Schoeninger (2010) and Hare et al. (1991), respectively. Fractionation values for diet-bone apatite are less well known, but available evidence suggests a range from $+8 \%$ to $+14 \%$ ( Tykot et al. 2009). On the basis of the reported collagen-apatite spacing of $+7 \%$, fractionation values for $\delta^{13} \mathrm{C}_{\text {ap }}$ were calculated by adding the spacing to the value of $\delta^{13} \mathrm{C}_{\mathrm{col}}$ of each source; this generates values concordant with those informed by previous works (Howland et al. 2003; Tykot et al. 2009). Samples of modern resources were also corrected for the Suess effect by adding $+1 \%$ to the $\delta^{13} \mathrm{C}_{\mathrm{col}}$ values (Katzenberg et al. 2012).

\section{Dietary Patterns across Time and Geographic Areas}

Figure 2 displays an isospace plot of $\delta^{13} \mathrm{C}_{\mathrm{col}}$ and $\delta^{15} \mathrm{~N}$ for the full data, using the fractionation values suggested by Bocherens and Drucker (2003) for animals and those suggested by Froehle, Kellner, and Schoeninger (2010) for plants (fractionation A). The isospace plot shows some differences in the isotopic values of human samples, corresponding to different areas and chronological periods. The most notable difference is observed between the later Late Holocene sample from North Mendoza and the later samples from the other two areas (South and Center Mendoza). Isotopic values of individuals from the northern sample are closer to values for maize and cacti, while the South and Center samples are closer to the values for animals and $C_{3}$ plants. The remaining samples are in an intermediate position and have overlapping distributions. It is noteworthy to mention that most samples display high intragroup dispersion.

Figure 3 shows density plots of the dietary proportions for each human sample based on bone collagen. Most of the samples present a high contribution of animals to the diet (with a proportion around 0.5 ), followed by $\mathrm{C}_{3}$ plants, while CAM and $\mathrm{C}_{4}$ plants have a very low contribution. A different pattern is observed in the later sample from North Mendoza, which has a higher proportion of maize than of $\mathrm{C}_{3}$ plants. It is also noteworthy that in Center and South Mendoza, the contribution of $\mathrm{C}_{3}$ plants is closer to the values obtained for animals. The correlation between the different sources was further explored to determine the extent to which it is possible to ascertain which food sources were being consumed together. A strong negative correlation in the posterior probabilities of diet proportions indicates that the food sources are indistinguishable when the available isotopic variables are used (Parnell

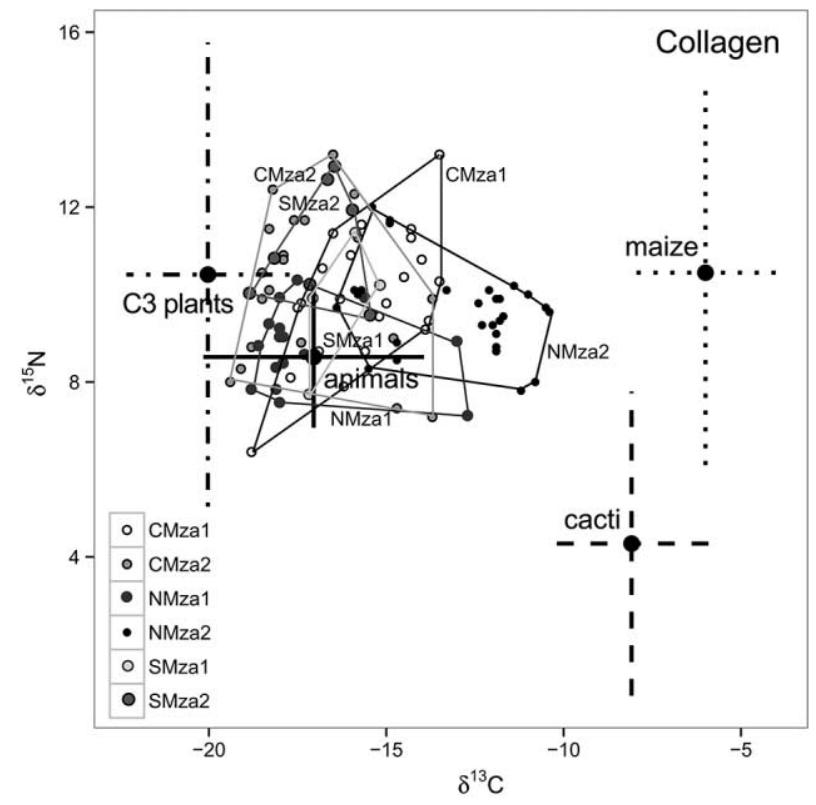

Figure 2. Isospace plot of $\delta^{13} \mathrm{C}_{\text {col }}$ (where "col" denotes collagen) and $\delta^{15} \mathrm{~N}$ for the resources and consumers grouped by geographic area and time period. The fractionation values used in this analysis correspond to set $\mathrm{A}$ for $\delta^{13} \mathrm{C}_{\text {col }}$ in table 1 . CMza = Center Mendoza; SMza = South Mendoza; NMza $=$ North Mendoza; see figure 1 . For each of these, $1=$ early Late Holocene (ca. 4,000-1,500 years BP), and 2 = later Late Holocene (1,500-200 years BP). A color version of this figure is available online. 

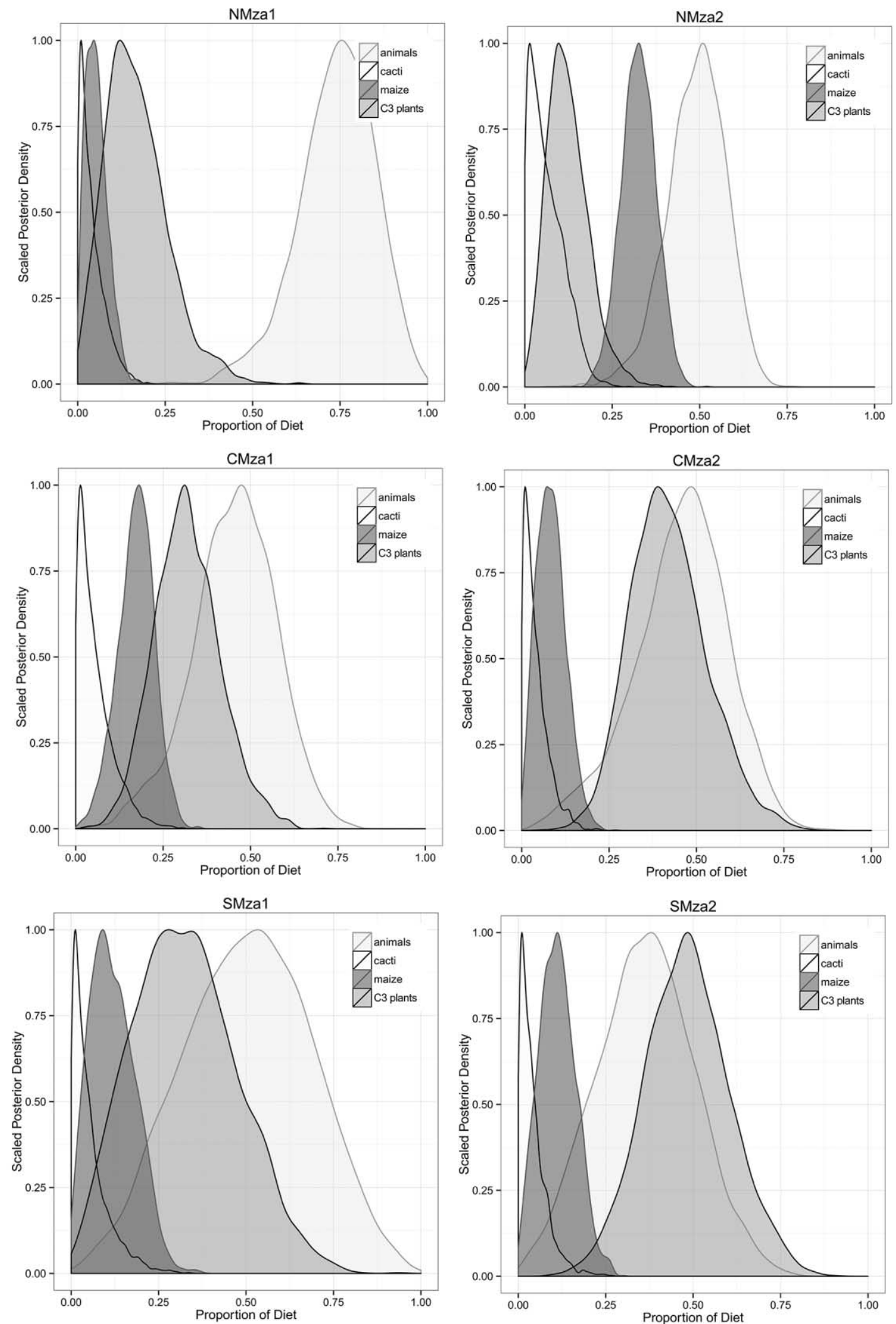

Figure 3. Density plots of dietary proportion for human samples by geographic area and time period estimated on the basis of $\delta^{13} \mathrm{C}_{\text {col }}$ (where "col" denotes collagen) and $\delta^{15} \mathrm{~N}$ from figure 2. CMza = Center Mendoza; SMza = South Mendoza; NMza = North Mendoza; see figure 1 . For each of these, 1 = early Late Holocene (ca. 4,000-1,500 years BP), and 2 = later Late Holocene (1,500200 years BP). A color version of this figure is available online. 
et al. 2013). In our case, the highest negative value was found between animals and $\mathrm{C}_{3}$ plants $(r=-0.88)$, indicating that the exact contribution of these resources to the protein portion of human diets might be hard to distinguish by using these two isotopes only.

The isospace plot for diet-bone apatite (fig. 4) shows that for most human samples, isotope values fall within the range of animals and $\mathrm{C}_{3}$ plants, with the exception of a few individuals of North Mendoza, whose results are closer to the $\mathrm{C}_{4}$ and CAM values. Accordingly, the posterior probabilities indicate that the contribution of animals and $\mathrm{C}_{3}$ plants to overall diet was very high in most samples, with the exception of the late North Mendoza sample (NMza2 in the figures), where the proportion of maize was higher than that of $\mathrm{C}_{3}$ plants, with a value of 0.20 (fig. 5). A strong negative correlation was also found between animals and $\mathrm{C}_{3}$ plants $(r=-0.83)$.

When a fractionation value of $1 \%$ o $\pm 0.3 \%$ was used for the $\delta^{13} \mathrm{C}_{\text {col }}$ of all sources (fractionation $\mathrm{B}$ ), as suggested by Bocherens and Drucker (2003), the samples showed an overall displacement toward the values of maize and cacti (fig. A1; figs. A1, A2 available online). The estimated proportions are similar to those previously obtained with different fractionation values (fig. A1). The main difference is the increase in the proportion of maize, reaching values around 0.25 in most of

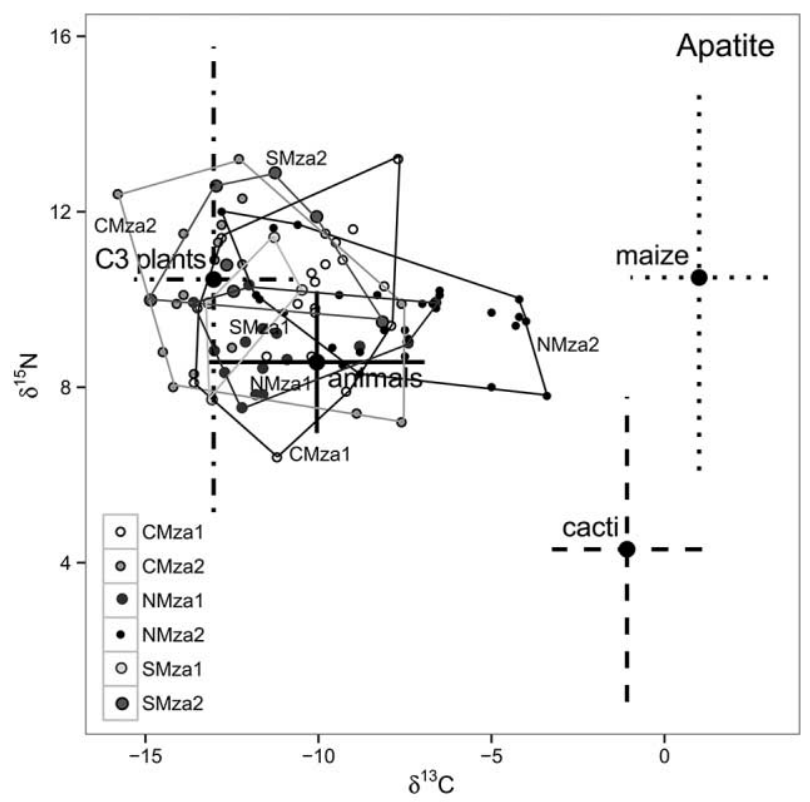

Figure 4. Isospace plot of $\delta^{13} \mathrm{C}_{\mathrm{ap}}$ (where "ap" denotes apatite) and $\delta^{15} \mathrm{~N}$ for the resources and consumers grouped by geographic area and time period. The fractionation values used in this analysis correspond to set $\mathrm{A}$ for $\delta^{13} \mathrm{C}_{\mathrm{ap}}$ in table 1 . CMza $=$ Center Mendoza; SMza = South Mendoza; NMza $=$ North Mendoza; see figure 1 . For each of these, $1=$ early Late Holocene (ca. 4,000-1,500 years BP), and 2 = later Late Holocene (1,500-200 years BP). A color version of this figure is available online. the samples analyzed. The highest contribution of this resource to the diet is observed in the late sample from North Mendoza. Fractionation values of $5 \%$ o $\pm 1.3 \%$ or for $\delta^{13} \mathrm{C}_{\text {col }}$ (fractionation C; Jim et al. 2006; Tykot et al. 2009) yielded a displacement of human samples in the isospace toward the $\mathrm{C}_{3}$ plants (fig. A1). Accordingly, the posterior densities indicate that, in most human samples, $\mathrm{C}_{3}$ plants account for more than $60 \%$ of consumed resources, except in the later sample of North Mendoza, in which animals are the most important resource in the diet (fig. A1). Maize has a significant contribution only in the later sample from North Mendoza. Finally, the analyses made with different fractionation values of bone collagen for each source, using the fractionation $\mathrm{D}$ setting, produced results similar to those obtained with the fractionation A values (fig. A1).

For bone apatite, the isoplot obtained with a discrimination value of $8 \%$ o $\pm 0.3 \%$ (fractionation $\mathrm{B}$ ) produced a slight displacement of human samples in the isoplot toward the values of $\mathrm{C}_{4}$ and CAM plants (fig. A2). Posterior densities show a pattern similar to the proportions obtained with fractionation $\mathrm{A}$ values (fig. A2). $\mathrm{C}_{4}$ plants have a significant contribution to the diet only in the later sample from North Mendoza and the early sample from Center Mendoza (25\% and 15\%, respectively). With discrimination values of $12 \%$ o $\pm 1.5 \%$ o for bone apatite (fractionation $\mathrm{C}$ ), the majority of human samples in the isoplot fall within the range of $\mathrm{C}_{3}$ plants (fig. A2). In most of the samples, $\mathrm{C}_{3}$ plants represent a proportion equal to or higher than 0.65 of overall diet (fig. A2). The only exception is the later sample from North Mendoza. Finally, the $\delta^{13} \mathrm{C}_{\mathrm{ap}}$ results using the range of values from fractionation $\mathrm{D}$ are similar to those obtained with a value of $8 \%$ o $\pm 0.3 \%$ (fig. A2).

\section{Discussion and Conclusion}

The Bayesian mixing model applied here provided a probabilistic assessment for relative source contributions in diet across the geographic areas and time periods analyzed. Our results showed that animals and $\mathrm{C}_{3}$ plants were the most commonly consumed resources in the three geographic areas during the Late Holocene. This is in agreement with a recent study that determined that remains of economically important wild $\mathrm{C}_{3}$ plants (such as Prosopis sp., Schinus polygamus, and Geoffroea decorticans) are frequently encountered in Late Holocene archaeological sites from Center and South Mendoza (Llano 2015). According to estimations based on collected and processed extant plants, these resources have a high nutritional content and high return, and thus they could have been important sources of energy in prehispanic societies (Llano 2015). For the Center and South Mendoza samples, our estimations suggest that animal resources contributed to the diet in proportions similar to those of $\mathrm{C}_{3}$ plants (figs. 3, 5). The only samples for which animals account for most of the resources consumed are the samples from North Mendoza. Overall, the results of this study differ from those 

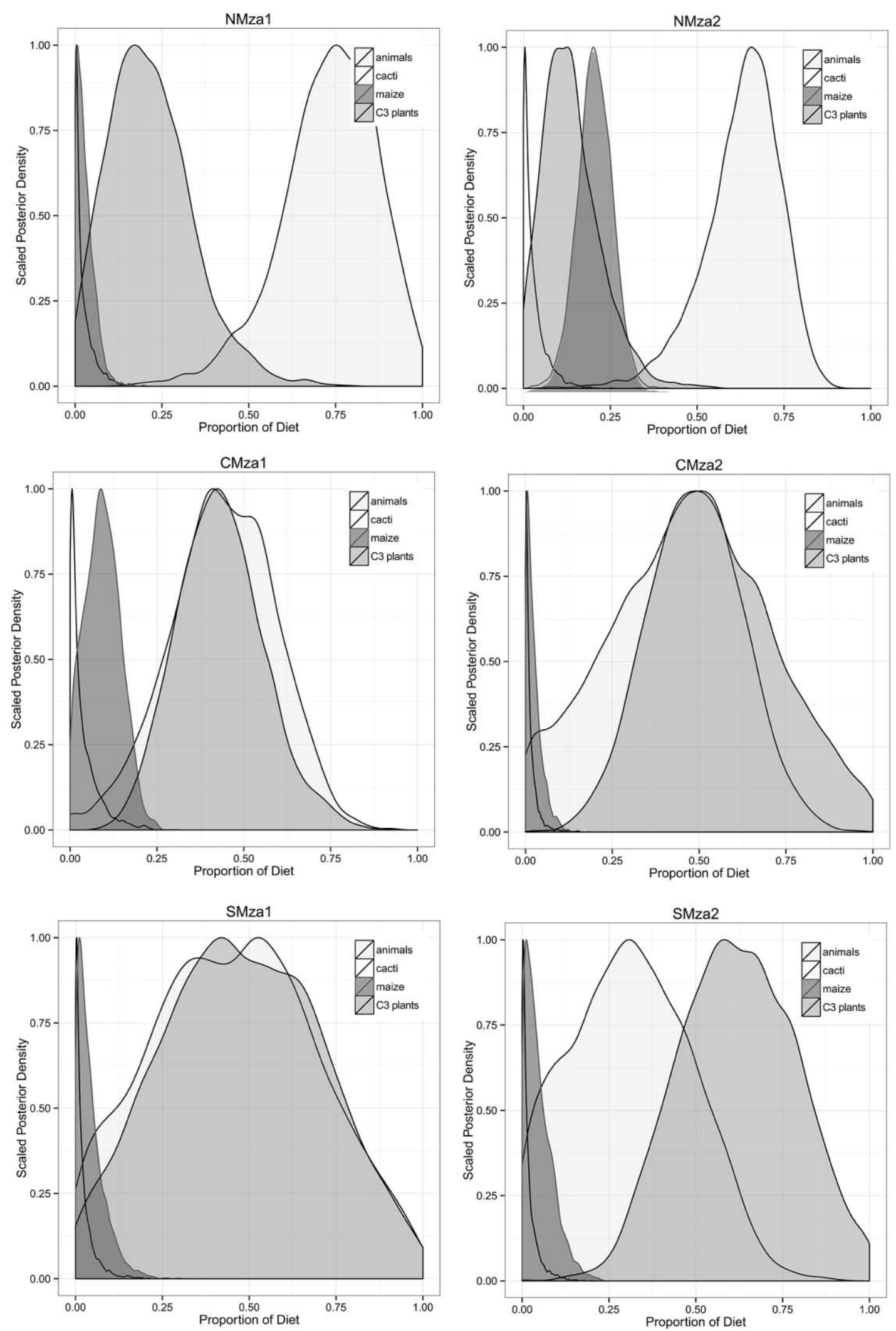

Figure 5. Density plots of dietary proportion for human samples by geographic area and time period estimated on the basis of $\delta^{13} \mathrm{C}_{\mathrm{ap}}$ (where "ap" denotes apatite) and $\delta^{15} \mathrm{~N}$ from figure 4. CMza = Center Mendoza; SMza = South Mendoza; NMza = North Mendoza; see figure 1 . For each of these, 1 = early Late Holocene (ca. 4,000-1,500 years BP), and 2 = later Late Holocene (1,500200 years BP). A color version of this figure is available online. 
of previous works that have emphasized the role of terrestrial herbivores in the diet of these populations. Particularly, the guanaco (Lama guanicoe), a camelid whose remains are frequently found in the archaeological record, was thought of as having a significant contribution (Gil et al. 2014), although no attempt has been made to estimate its exact proportion in the diet. Moreover, those studies that analyze isotope values are mostly based on collagen and apatite $\delta^{13} \mathrm{C}$, making the contribution of animals hard to set apart from that of $\mathrm{C}_{3}$ plants. As we showed here, these resources can be discriminated in the bivariate isospace to a greater or lesser extent, depending on the fractionation value used. However, because there is a negative correlation between the posterior probabilities of diet proportions of $\mathrm{C}_{3}$ plants and terrestrial herbivores, the balance between them is difficult to determine exactly. Although for these populations it is usually assumed that the protein component of the diet derives from animal resources, the $\mathrm{C}_{3}$ plants that most probably were consumed present variable percentages of proteins, ranging, for example, from 6\% to 21\% in Prosopis flexuosa and G. decorticans, where carbohydrates represent $69 \%$ and $12 \%$, respectively (Llano 2015). Therefore, these resources could have contributed to the protein component of human diets at a high proportion. Such discordance between zooarchaeological and isotopic evidence is probably due to the fact that the better preservation of large-animal bones can lead to overestimation of the importance of these resources, to the detriment of others that are relatively poorly preserved and/or more difficult to recover (such as macro- and microremains of plants; Hather and Mason 2002).

The contribution of domesticated plants-especially maize - to the diet of prehispanic populations that inhabited the area under study has been debated for decades (Canals Frau 1956; Gil et al. 2006, 2014; Lagiglia 2001). Because Mendoza Province is located between two geographic regions that by the later Late Holocene were inhabited by populations with markedly different subsistence strategies, hunter-gatherers in the south and farmers in the north, it is regarded as the southern limit of agriculture in America. Our results indicate that maize had a very low contribution to the diet of these populations (less than 15\% in Center and less than $5 \%$ in South Mendoza). The only exception is the later sample from North Mendoza, which has an average proportion of $25 \%$ of maize, although there is large variation within the sample and some individuals have isotope values compatible with a higher proportion of $\mathrm{C}_{3}$ than of $\mathrm{C}_{4}$ plants. These results are far from the dietary importance attributed to maize between 1,200 and 600 years $\mathrm{BP}$, when this resource was suggested to have contributed as much as $50 \%$ of the overall diet (Gil, Neme, and Tykot 2011; Gil et al. 2014). As Llano and Ugan (2014) pointed out, such estimations might be biased because the archaeological research has systematically neglected the role of CAM plants, whose $\delta^{13} \mathrm{C}$ values overlap the range of $\mathrm{C}_{4}$ plants. According to these authors, the human-collagen $\delta^{13} \mathrm{C}$ values could have been obtained if cacti contributed as little as $5 \%-20 \%$ of dietary carbon. The Bayesian methods allowed us to evaluate the proportion of resources by analyzing $\delta^{13} \mathrm{C}$ and $\delta^{15} \mathrm{~N}$ simultaneously, which is relevant for distinguishing between maize and cacti with nonoverlapping $\delta^{15} \mathrm{~N}$ signatures (moreover, the correlation between posterior probabilities for these two resources is very low). Our results show that the contribution of cacti is negligible in the samples analyzed.

The importance of $\mathrm{C}_{3}$ plants in all Mendoza regions and the contribution of maize in North Mendoza are observed with $\delta^{13} \mathrm{C}$ values of both bone collagen and apatite, indicating that the two measures are reflecting the same dietary trend. This result also suggests that, in the region under study, there was a similar isotopic contribution from protein and nonprotein dietary sources (Tykot et al. 2009). The most highlighted difference between the $\delta^{13} \mathrm{C}$ values of bone collagen and apatite is the higher proportion of $\mathrm{C}_{3}$ vegetables derived from the latter. Because $\delta^{13} \mathrm{C}_{\text {ap }}$ is a better reflection of the whole diet (Tykot et al. 2009), this result indicates that $C_{3}$ plants might have had a greater importance for Late Holocene populations from Mendoza than previously suggested (Gil et al. 2006, 2014).

One important finding of this study is the dependence of the estimated diet composition on the fractionation values incorporated into the models. Variation in fractionation values is a function of several causal factors that include local environment, trophic level, taxon, and sampled tissue, among others (Phillips et al. 2014). Determining the amount of change in isotope ratios as they are incorporated from resources into the consumers' tissue is widely acknowledged as a central issue for attaining accurate diet reconstructions in ecology (Bond and Diamond 2011; Caut, Angulo, and Courchamp 2009), although their variation is not usually taken into account in paleodietary reconstructions in archaeology. In particular, studies that analyze human isotope values in southern South America have used a single fractionation value for all resources, $+3 \%$ for $\mathrm{N}$ and ranging from $+1 \%$ to $+5 \%$ for C (Gil et al. 2006, 2014; Llano and Ugan 2014; Tessone et al. 2009). This is likely due to limitations of the qualitative methods that cannot easily incorporate multiple values for different resources.

Here, different values derived from controlled experimental and observational studies were used in order to incorporate variability in fractionation factors into the mixing models. Our results show that estimated proportions of each diet component were significantly influenced by the isotope fractionation values of $\delta^{13} \mathrm{C}$ and $\delta^{15} \mathrm{~N}$. Particularly affected was the estimation of the relative proportions of maize and $\mathrm{C}_{3}$ plants.

Overall, our study highlights two main aspects that could be addressed in order to attain more confident and precise assessments of the diet composition of prehispanic populations from Mendoza. First, no information on fractionation values for local resources is available; obtaining such data is a requisite for estimating more precisely the proportion at 
which each resource was incorporated into the diets. Second, increasing the number of different isotopes analyzed beyond $\mathrm{C}$ and $\mathrm{N}$ for both the consumer and the potential resources is a necessary step for determining diet composition in terms of actual animal and plant species rather than broad categories of sources, such as those used here and in previous studies. Other commonly used isotopes, such as $\delta^{34} \mathrm{~S}$ (sulfur), $\delta^{87} \mathrm{Sr}$ (strontium), $\delta^{18} \mathrm{O}$ (oxygen, which is available for human samples from Mendoza but not for the resources; Ugan et al. 2012), and $\delta \mathrm{D}$ (deuterium), which vary geographically and can be differentially absorbed for plants and animals occupying different ecological niches (Hobson 1999), could contribute to better discrimination between different resources with different isotopic signals.

\section{Acknowledgments}

We would like to thank the three anonymous referees for their helpful comments. This study was supported by grants from Universidad Nacional de La Plata (PI 11/N742) and Consejo Nacional de Investigaciones Científicas y Tecnológicas (PIP 0428) to V. Bernal.

\section{References Cited}

Arcini, Caroline, Torbjörn Ahlström, and Göran Tagesson. 2014. Variations in diet and stature: are they linked? Bioarchaeology and paleodietary Bayesian mixing models from Linköping, Sweden. International Journal of Osteoarchaeology 24:543-556.

Bocherens, Hervé, and Dorothée Drucker. 2003. Trophic level isotopic enrichments for carbon and nitrogen in collagen: case studies from recent and ancient terrestrial ecosystems. International Journal of Osteoarchaeology 13:46-53.

Bond, Alexander L., and Antony W. Diamond. 2011. Recent Bayesian stableisotope mixing models are highly sensitive to variation in discrimination factors. Ecological Applications 21:1017-1023.

Canals Frau, Salvador. 1956. La cultura de Agrelo (Mendoza). Runa 7(2): 169-187.

Caut, Stéphane, Elena Angulo, and Franck Courchamp. 2009. Variation in discrimination factors $\left(\Delta^{15} \mathrm{~N}\right.$ and $\left.\Delta^{13} \mathrm{C}\right)$ : the effect of diet isotopic values and applications for diet reconstruction. Journal of Applied Ecology 46: $443-453$.

Drake, Brandon Lee, Wirt H. Wills, Marian I. Hamilton, and Wetherbee Dorshow. 2014. Strontium isotopes and the reconstruction of the Chaco regional system: evaluating uncertainty with Bayesian mixing models. PLoS ONE 9(5):e95580. doi:10.1371/journal.pone.0095580.

Froehle, Andrew, Corina Kellner, and Margaret Schoeninger. 2010. Focus: effect of diet and protein source on carbon stable isotope ratios in collagen; follow up to Warinner and Tuross (2009). Journal of Archaeological Science 37(10):2662-2670.

Gil, Adolfo, Gustavo Neme, and Robert Tykot. 2011. Stable isotopes and human diet in central western Argentina. Journal of Archaeological Science 38:1331-1340

Gil, Adolfo, Robert Tykot, Gustavo Neme, and Nicole Shelnut. 2006. Maize on the frontier: isotopic and macrobotanical data from central-western Argentina. In Histories of maize: multidisciplinary approaches to the prehistory, biogeography, domestication, and evolution of maize. John $\mathrm{E}$. Staller, Robert Tykot, and Bruce Benz, eds. Pp. 199-214. New York: Academic Press.

Gil, Adolfo, Ricardo Villalba, Andrew Ugan, Valeria Cortegoso, Gustavo Neme, Catalina Michieli, Paula Novellino, and Víctor Durán. 2014. Iso- topic evidence on human bone for declining maize consumption during the Little Ice Age in central western Argentina. Journal of Archaeological Science 49:113-227.

Hare, P. Edgar, Marilyn L. Fogel, Thomas W. Stafford Jr., Alva D. Mitchell, and Thomas C. Hoering. 1991. The isotopic composition of carbon and nitrogen in individual amino acids isolated from modern and fossil proteins. Journal of Archaeological Science 18:277-292.

Hather, Jon G., and Sarah L. R. Mason. 2002. Introduction: some issues in the archaeobotany in hunter-gatherers. In Hunter-gatherer archaeobotany: perspectives from the northern temperate zone. Sarah L. R. Mason and Jon G. Hather, eds. Pp 1-14. London: Institute of Archaeology, University College London.

Hobson, Keith A. 1999. Tracing origins and migration of wildlife using stable isotopes: a review. Oecologia 120:314-326.

Hopkins, John B., III, and Jake M. Ferguson. 2012. Estimating the diets of animals using stable isotopes and a comprehensive Bayesian mixing model. PLoS ONE 7(1):e28478. doi:10.1371/journal.pone.0028478.

Howland, Michael R., Lorna T. Corr, Suzanne M. M. Young, Vicky Jones, Susan Jim, Nikolaas J. van der Merwe, Alva D. Mitchell, and Richard P. Evershed. 2003. Expression of the dietary isotope signal in the compoundspecific $\delta^{13} \mathrm{C}$ values of pig bone lipids and amino acids. International Journal of Osteoarchaeology 13:54-65.

Jim, Susan, Vicky Jones, Stanley H. Ambrose, and Richard P. Evershed. 2006. Quantifying dietary macronutrient sources of carbon for bone collagen biosynthesis using natural abundance stable carbon isotope analysis. British Journal of Nutrition 95(6):1055-1062.

Katzenberg, M. Anne, Hugh G. McKenzie, Robert J. Losey, Olga I. Goriunova, and Andrzej Weber. 2012. Prehistoric dietary adaptations among hunter-fisher-gatherers from the Little Sea of Lake Baikal, Siberia, Russian Federation. Journal of Archaeological Science 39:2612-2626.

Lagiglia, Humberto. 2001. Los orígenes de la agricultura en la Argentina. In Historia argentina prehispánica. Eduardo Berberian and Axel Nielsen, eds. Pp. 41-81. Cordoba: Brujas.

Layman, Craig A., Marcio S. Araujo, Ross Boucek, Caroline M. HammerschlagPeyer, Elizabeth Harrison, Zachary R. Jud, Philip Matich, et al. 2012. Applying stable isotopes to examine food-web structure: an overview of analytical tools. Biological Reviews 87:545-562.

Llano, Carina. 2015. On optimal use of a patchy environment: archaeobotany in the Argentinean Andes (Argentina). Journal of Archaeological Science 54:182-192.

Llano, Carina, and Andrew Ugan. 2014. Alternative interpretations of intermediate and positive $\delta^{13} \mathrm{C}$ isotope signals in prehistoric human remains from southern Mendoza, Argentina: the role of CAM species consumption. Current Anthropology 55:822-831.

Moore, Jonathan W., and Brice X. Semmens. 2008. Incorporating uncertainty and prior information into stable isotope mixing models. Ecology Letters 11:470-480.

Parnell, Andrew C., Donald L. Phillips, Stuart Bearhop, Brice X. Semmens, Eric J. Ward, Jonathan W. Moore, Andrew L. Jackson, Jonathan Grey, David J. Kelly, and Richard Inger. 2013. Bayesian stable isotope mixing models. Environmetrics 24:387-399.

Phillips, Donald L. 2001. Mixing models in analyses of diet using multiple stable isotopes: a critique. Oecologia 127:166-170.

Phillips, Donald L., and Jillian W. Gregg. 2001. Uncertainty in source partitioning using stable isotopes. Oecologia 127:171-179.

Phillips, Donald L., Richard Inger, Stuart Bearhop, Andrew L. Jackson, Jonathan W. Moore, Andrew C. Parnell, Brice X. Semmens, and Eric J. Ward. 2014. Best practices for use of stable isotope mixing models in foodweb studies. Canadian Journal of Zoology 92:823-835.

Salgán, Laura, Hugo Tucker, Leandro Luna, and Claudia Aranda. 2012. Estudios arqueológicos y bioarqueológicos en la cuenca media del Río Malargüe (Provincia de Mendoza): el sitio Bajada de las Tropas 1. Relaciones de la Sociedad Argentina de Antropología 37(1):113-135.

Schwarcz, Henry P. 1991. Some theoretical aspects of isotope paleodiet studies. Journal of Archaeological Science 18:261-275.

Semmens, Brice X., Eric J. Ward, Jonathan W. Moore, and Chris T. Darimont. 2009. Quantifying inter- and intra-population niche variability using hierarchical Bayesian stable isotope mixing models. PloS ONE 4(7): e6187. doi:10.1371/journal.pone.0006187.

Stock, Brian C., and Brice X. Semmens. 2013. MixSIAR GUI user manual, version 1.0. http://conserver.iugo-cafe.org/user/brice.semmens/MixSIAR. 
Tessone, Augusto, A. Francisco Zangrando, Gustavo Barrientos, Rafael Goñi, Héctor Panarello, and Mariana Cagnoni. 2009. Stable isotope studies in the Salitroso Lake Basin (southern Patagonia, Argentina): assessing diet of Late Holocene hunter-gatherers. International Journal of Osteoarchaeology 19:297-308.

Tykot, Robert, Fernanda Falabella, María T. Planella, Eugenio Aspillaga Lorena Sanhueza, and Cristian Becker. 2009. Stable isotopes and archaeol- ogy in central Chile: methodological insights and interpretative problems for dietary reconstruction. International Journal of Osteoarchaeology 19: 156-170.

Ugan, Andrew, Gustavo Neme, Adolfo Gil, Joan Coltrain, Robert Tykot, and Paula Novellino. 2012. Geographic variation in bone carbonate and water $\delta^{18} \mathrm{O}$ values in Mendoza, Argentina and their relationship to prehistoric economy and settlement. Journal of Archaeological Science 39:2752-2763. 